\title{
Concept for a Supply Chain Digital Twin
}

\author{
Sergey Yevgenievich Barykin \\ Graduate School of Service and Trade, \\ Peter the Great St. Petersburg Polytechnic University, \\ Polytechnicheskaya, 29, 195251, St. Petersburg, Russian Federation. \\ E-mail: sbe@list.ru
}

\author{
Andrey Aleksandrovich Bochkarev \\ St. Petersburg School of Economics and Management, \\ Department of Logistics and Supply Chain Management, \\ National Research University, Higher School of Economics, \\ Saint-Petersburg branch, Str. Kantemirovskaya, 3A, 194100, St. Petersburg, Russian Federation. \\ E-mail: abochkerev@hse.ru \\ Olga Vladimirovna Kalinina \\ Graduate School of Service and Trade, \\ Peter the Great St. Petersburg Polytechnic University, \\ Polytechnicheskaya, 29, 195251, St. Petersburg, Russian Federation. \\ E-mail: olgakalinina@bk.ru \\ Vladimir Konstantinovich Yadykin \\ Competence Center of the National Technological Initiative, \\ Direction of New production Technologies, Institute of Advanced Production Technologies, \\ Peter the Great St. Petersburg Polytechnic University, \\ Polytechnicheskaya, 29, 195251, St. Petersburg, Russian Federation. \\ Corresponding author: v.yadikin@mail.ru
}

(Received February 17, 2020; Accepted August 19, 2020)

\begin{abstract}
There is currently a discussion going on in the scientific community about using digital twins and modeling to manage risks in the supply chains. This need for constructing digital twins is caused by the low reliability and stability of supply chains due to the faults in their operation. These faults are a result of risks in the supply chains which can be consolidated into two types. The first type is operational risks. These are the current risks of the supply chain itself caused by an uncertainty of supply and demand as well as by an obstructed flow of information along the supply chain. The second type is critical risks caused by force majeure. These risks disrupt the normal operation of the supply chain and critically reduce the most important performance indicators of the company such as annual income and profits. Risks happen due to natural or man-made causes such as fires and floods in the distribution centers or at production facilities, legal disputes with suppliers, strikes, terrorist attacks on logistics facilities and others. Dynamic simulation and analytical optimization are two dominant technologies for managing risks of the supply chains, which helps to increase their reliability and stability if failures occur. Through optimizing and simulating of the supply chains, companies can generate new information about the impact of failure and influence the supply chain and its performance by looking at various scenarios that simulate the locations of failures, the duration and recovery policies. An analysis of the literary sources shows that there is no single approach to build the concept for a supply chain digital twin. This article gives an overview of the literature according to this problem and offers the author's point of view on the concept for a supply chain digital twin.
\end{abstract}

Keywords - Supply chains, Optimization, Simulation, Digital twin. 
International Journal of Mathematical, Engineering and Management Sciences

Vol. 5, No. 6, 1498-1515, 2020

https://doi.org/10.33889/IJMEMS.2020.5.6.111

\section{Introduction}

Creating a sustainable supply chain means balancing between reliability and flexibility. Both of these supply chain properties can act as airbags against uncertainty and should be taken into account when planning. Outdated logistics solutions have not justified themselves in the digital age. Decentralized communication gives way to more accurate and modern solutions.

The combination of simulation, optimization, and data analytics is the basic technology allowing a fairly detailed model of the real supply chain - its digital twin - to be created. The idea behind creating a digital twin is to manage the risks in supply chains, thus making them more reliable and sustainable in the event of any failures.

Simulation and optimization are those basic technologies that are used primarily as strategic planning tools. However, the quality of making decisions when risks occur depends drastically on the timely availability of relevant data since decisions should often be made immediately.

Modern technologies allow collecting large amounts of data on supply chains online: supply failure probabilities and suppliers' data such as their financial condition and production capabilities. The management technologies used in supply chains allow the critical hot spots to be identified and give timely warnings about incidents which can have a critical impact on the supply chain.

All of this real-time data regarding failures can be included in the simulation model along with natural, financial or political risks. Integrating simulation and optimization with online or "live" data makes it possible to use simulations for strategic planning. A number of scientific studies (Ivanov et al., 2019; Ivanov and Dolgui, 2019a; Ivanov and Dolgui, 2019b; Popkov et al., 2019) show that this kind of strategic simulation of a supply chain, which includes optimization models and data analytics, is a supply chain digital twin. This view, in our opinion, is a reflection of the prevailing practice of planning and modeling supply chains but not a result of the scientific understanding of the concept of a supply chain digital twin (Klochkov et al., 2019).

The concept for a supply chain digital twin should answer the following questions. Firstly, what combination of simulation modeling, optimization, and data analytics makes up the full range of technologies needed to create a digital twin model of the supply chain?

Secondly, how accurate or detailed should the simulation model be so that it can be called a supply chain digital twin and on what issues should we get an answer in the modeling process?

Thirdly, which concept of the supply chain digital twin is the most efficient? What is the optimal combination of analytical optimization and dynamic simulation? Here two main approaches are considered:

a) analytical optimization is a complement to the dynamic simulation;

b) dynamic simulation is a complement to the analytical optimization.

\section{Literature Overview of Using Industry 4.0 Solutions in SCM}

In 2011, the concept of Industry 4.0 entered scientific parlance, with the prospect of joining things and services into a global commercial network. Speaking more broadly, Industry 4.0 characterizes the current development trend of automation and data exchange. It is a new level of organizing production and value chain management over the whole life cycle of manufactured goods. 
International Journal of Mathematical, Engineering and Management Sciences

Vol. 5, No. 6, 1498-1515, 2020

https://doi.org/10.33889/IJMEMS.2020.5.6.111

Industry 4.0 is usually described by pointing to the key technologies of today and the near future: big data, the Internet of Things, virtual and augmented reality, additive manufacturing (3D printing), digital design and modeling, artificial intelligence, materials with specific properties, self-driving transport and robotics (Tarasov, 2018).

The paper (Petrović et al., 2020) describes the specific mechanism (OPIL) to show and try to address the challenge of incorporating robots and IT infrastructure into logistics automation.

The authors suggest implementing omnidirectional automated guided vehicles (AGV) into the robotic system for process automation. The OPIL structure includes four layers of computerization (from zero to three). Layer One architecture components interact with the physical world (Layer Zero). They communicate with the outer world by sensing (Sensor Agent Node), acting (Robotic Agent Nodes) or communicating via interface with personnel (Human Agent Nodes). The OPIL framework features robot agents with two basic operation modes: product transportation inside a production plant and product handling (loading and unloading) to transport the latter from the plant to the AGV and other way around. The Cyber Physical Middleware (Layer Two) decouples the components communicating with the physical world from other software components and enables interoperability and communication between the Layer One IoT (Internet of Things) nodes and other OPIL components. The Layer 3 is the highest level of OPIL containing the full set of services the platform can offer to the end user. This layer consists of three main modules: Task Planner, Advanced HMI (Human-machine interface), and the Sensing and Perception module. The Task Planner module is built in to provide motion tasks planning of various robot agents present in the OPIL architecture. It becomes possible through the Motion Task Planning submodule. It is also required for making and optimizing tasks to be sent to various agents of the OPIL architecture through Business Process Optimization submodule. Task Supervisor submodule performs monitoring and execution of the tasks dispatched to the agents. The Advanced HMI OPIL node consists of three different submodules. There are two key features of the Task Monitoring and Control submodule: it provides subscription and visualization of information present at OPIL as well as controls operations, tasks and other actions scheduled by OPIL or personnel. The Task Parameterization submodule is necessary to collect and parameterize data collected from Enterprise Applications. Based on the taskrelated information sent by the Task Monitoring and Control submodule as well as task-specific parameters collected from the Task Parameterization submodule, the Task Specification submodule formulates a new task. The Sensing and Perception component allows OPIL to generate information necessary for safe and accurate motion planning and provide it to the OPIL system's actors such as Robotic Agent Nodes (RAN).

This open platform for innovations in logistics, which was originally developed by (Petrović et al., 2020) offers a new approach to digital logistics control. But the system overlooks specific features of supply chain digital transformation. In our point of view, the key challenge of impacting digital transformation of supply chains is the challenging ability to control a large-scale global logistics networks notwithstanding constant advancement of computer systems. (Vorobyov et al., 2019) assumes that rapid changes make a person powerless and pushes people to effective cooperation, which is not in the nature of humans. By all means, artificial intelligence and robotics facilitate and automate a large number of tasks. However, one should consider the following. Rapid growth of computer efficiency pushes down the market value of an economic agent and makes people cooperate while designing the logistics networks contradicting the economical traditions of competitiveness existing prior to digitalization. This is a very important fact as the supply chain stakeholder's interests shall not be set aside. 
International Journal of Mathematical, Engineering and Management Sciences

Vol. 5, No. 6, 1498-1515, 2020

https://doi.org/10.33889/IJMEMS.2020.5.6.111

According to (Kauf, 2019), smart logistics includes implementation of a wide range of tools to fully automate logistic tasks, as well as novel intelligent technologies and smart solutions, contributing to logistic system's functioning. These are:

- Intelligent transportation systems (ITS);

- Autonomous logistics. These are the systems making it possible to provide unmanned and autonomous movement of people and cargo with minimum labour force;

- Physical internet. It provides the ability to move the goods anywhere in short amount of time most effectively reaching economic, social and environmental balance;

- Intelligent cargo. These are goods having the information about their place of location, destination, time of delivery to the place of destination and reloading personnel;

- Self-organizing logistics. It is a special system with the ability to operate with low effort from the manager and engineer side.

All these features described in the paper by Kauf (2019) should be investigated and implemented into the system in order to develop the concept for the supply chain digital twin. This is the key element of our research.

Le et al. (2020) tried to measure customer satisfaction with the logistics services regarding port service delivery and proved the following hypothesis:

H1: Empathy improves quality of services (expectation + )

H2: Reliability improves quality of services (expectation + )

H3: Assurance improves quality of services (expectation + )

H4: Responsiveness improves quality of services (expectation + )

H5: Tangibles improve quality of services (expectation + )

H6: Quality of service has a positive impact on customer satisfaction (expectation + )

The work Le et al. (2020) shows the service flow moving from port staff to customers via the Service delivery system using hard (tangible) and soft (intangible) platforms (indicated by red arrows). Both financial and information flows are indicated by blue arrows. Customers satisfaction grows in the process of using services thanks to the stated components.

We agree that customer satisfaction with Port's logistics services is directly connected to the overall service quality. It means that the supply chain digital network design should include those parameters mentioned above.

Various points of view exist on the key technologies of Industry 4.0. The work Essakly et al. (2019) points out that there are five solutions of Industry 4.0: predictive production control, decentralized automated guided vehicles, additive manufacturing, digital twins, and digitally assisted assembly. According to the authors, the connection between the Industry 4.0 solutions and these pillars of technology can be represented as follows.

Thus, digital twins of the production process include such technologies as simulation, the industrial Internet of Things and big data. 
International Journal of Mathematical, Engineering and Management Sciences

Vol. 5, No. 6, 1498-1515, 2020

https://doi.org/10.33889/IJMEMS.2020.5.6.111

Unity Technologies (USA) provides an alternative view of the range of key Industry 4.0 technologies in supply chains. The authors have given the name Logistics 4.0 to the application of Industry 4.0 technologies in logistics and supply chain management. According to analysts from this company, the list of key technologies is as follows: Open and Flexible Operations Footprint; Predictive Inbound Logistics Management (Big Data); No Warehouse in Supply Chain; Autonomous FTS on open area steered by production machine; Predictive Delivery Management; Autonomous Transportation Vehicle / Equipment (Logistics 4.0 and smart supply chain management in Industry 4.0, https://www.i-scoop.eu/industry-4-0/supply-chain-management-scm-logistics/ ).

The necessary future steps for Logistics 4.0 and Supply Chain 4.0 were explained in (https://www.iscoop.eu/industry-4-0/supply-chain-management-scm-logistics/).

The main technological trends of Industry 4.0 are digital design and simulation, new materials, and additive manufacturing. These technological areas have received more attention recently from hightech industry businesses, the government, and the science and business communities. In 2016, Russian companies listed in the yearly national rating of fast-growing high-tech companies "TechUspech" participated in a survey in which, in particular, they answered the question about which current technology trends they consider to be an opportunity to create new products or give new properties to already existing positions (Borovkov et al., 2018).

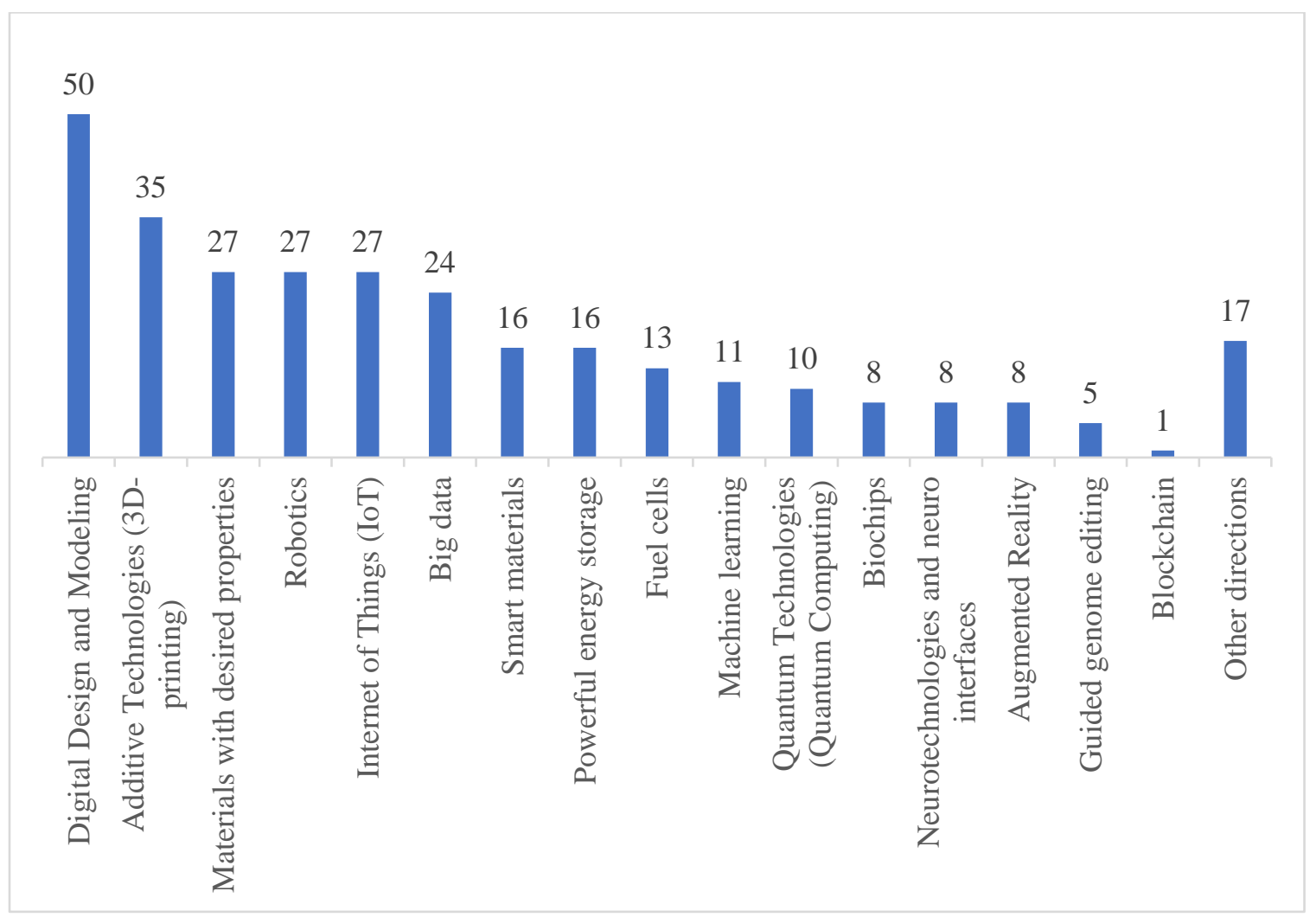

Figure 1. Answers to the question "Which of the following areas your company considers an opportunity to create new products or feature new properties to already existing positions" (percent of all surveyed companies) 
International Journal of Mathematical, Engineering and Management Sciences

Vol. 5, No. 6, 1498-1515, 2020

https://doi.org/10.33889/IJMEMS.2020.5.6.111

According to the results of the survey, the top five technologies were generally associated with Industry 4.0 (Figure 1):

- digital design and simulation (50\% of companies mentioned this set of technologies);

- additive manufacturing (3D-printing) (35\%);

- materials with specific properties $(27 \%)$;

- robotics $(27 \%)$;

— Internet of Things (IoT) (27\%).

Ivanov and Dolgui (2019a) in his paper presents a circuit diagram of a digital twin as a triad Digital Twins: Simulation + Optimization + Data Analytics. Besides simulation, optimization, and data analytics, in his paper he also adds the following to the key technologies of supply chain digital twins: RFID, the Internet of Things (IoT), track and trace systems (T\&T), online risk databases.

The diagram for forming a source database for scientific review on the topic of a digital twin concept is presented in Figure 2.

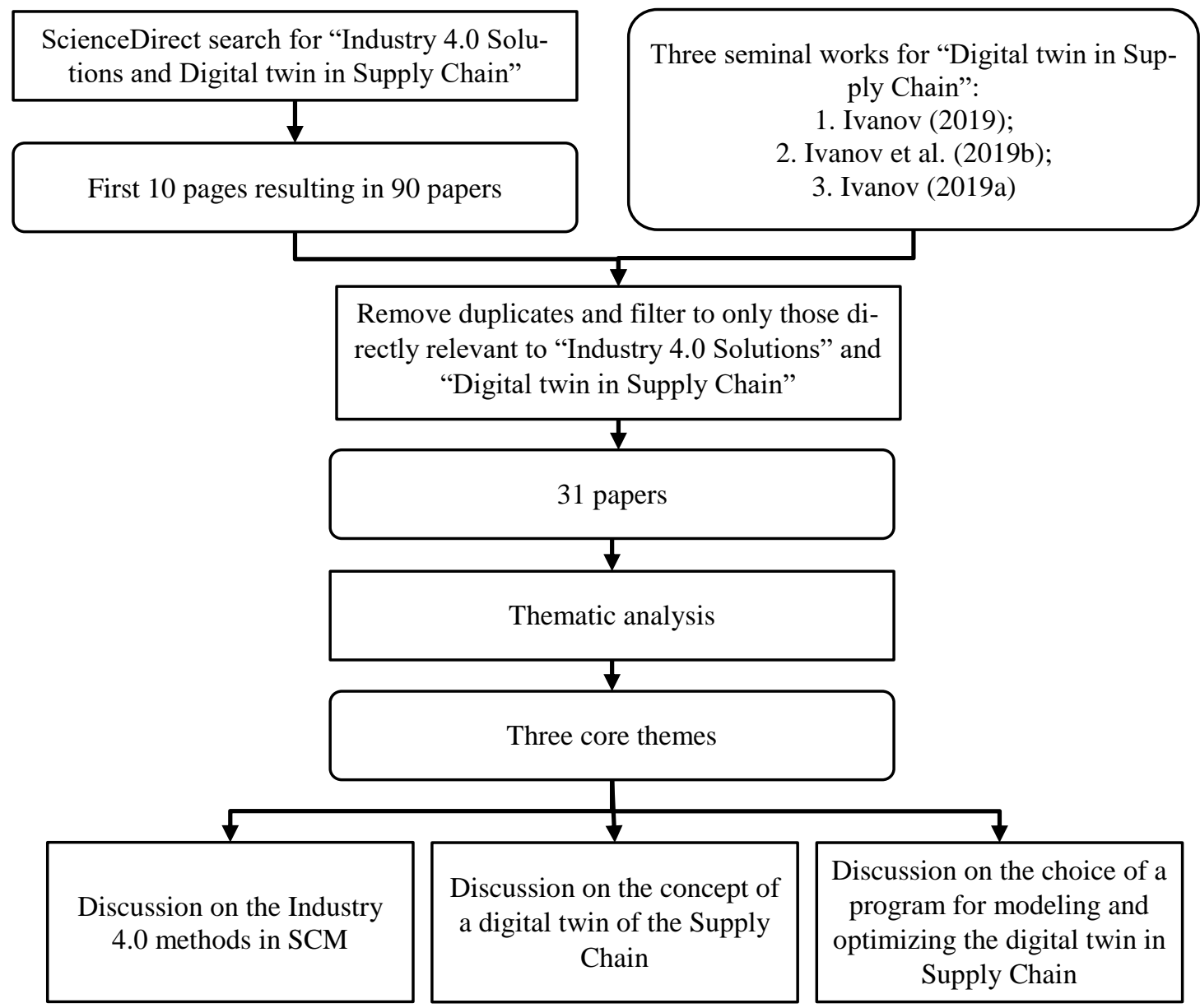

Figure 2. Diagram of research method (developed by the authors) 
International Journal of Mathematical, Engineering and Management Sciences

Vol. 5, No. 6, 1498-1515, 2020

https://doi.org/10.33889/IJMEMS.2020.5.6.111

A.I. Borovkov provides the following definition: a digital twin is a collection of complex multidisciplinary mathematical models highly appropriate for real materials, physical facilities / constructions / machines / devices ... / technical and cyber-physical systems, physical-mechanical processes (including technological and manufacturing processes), which can be described by 3D unsteady and non-linear partial differential equations. A digital twin should and is able to solve the issues of the place and object of measurement. In other words, it can point to critical areas where sensors must be installed as well as key features necessary for measuring deformation, temperature, pressure, vibrodisplacement, vibro-acceleration, and other criteria. Upon completion of all measurements the system should be able to store, process, transfer, and protect large amounts of data (big data). It is of key importance to distinguish digital twins from digital shadows. The latter are the systems of links and connections describing the average behavior of a real object/product in normal work conditions. These systems are stored in redundant big data received from a real object/product using multiple sensors and industrial internet technologies (Borovkov and Ryabov, 2019). The analysis of literature shows that the range of technologies supply chain digital twins are based on is fairly wide. Risk management, supply chain monitoring, and network optimization (NOM) should be added to the key technologies listed above.

Table 1 presents an attempt to summarize the research on using Industry 4.0 solutions in logistics.

Thus, there is no single opinion in the scientific community around which Industry 4.0 methods and technologies are used in logistics.

By analyzing the literature presented in Table 1, the following conclusions and summaries can be made:

a) Most of the authors agree that supply chain digital twins are based on simulation, optimization, and data analytics. Likewise, big data, supply chain design, and network optimization are often added to the range of the key technologies of a supply chain digital twin.

b) The importance of a technology like supply chain monitoring is underlined as a key technology of supply chain digital twins only in two papers, while supply chain risk analytics is mentioned in three. In our opinion, this is due to the fact that these technologies are mainly associated with physical supply chains and not with their digital twins. Cyber security as well is not considered by most of the authors to be a key technology for a supply chain digital twin.

c) Among other Industry 4.0 technologies, which can be used in logistics and supply chain management, the authors most frequently mention cloud computing, RFID, QR-code, and autonomous vehicle / equipment transportation as well as information technology like ERP, SCM, MES, CRM, PLM, and others.

d) It is noteworthy that all the papers on the subject were written in 2018 - March 2020. For this reason, it is currently difficult to talk about any kind of evolution regarding the opinion of experts on the issue of using Industry 4.0 solutions in managing supply chains. In a number of papers, for example Ivanov (2018), Ivanov et al. (2019) and Medini et al. (2019), the majority of the key Industry 4.0 technologies is considered as such in supply chain management. However, not all authors are in agreement on the topic. 
International Journal of Mathematical, Engineering and Management Sciences

Vol. 5, No. 6, 1498-1515, 2020

https://doi.org/10.33889/IJMEMS.2020.5.6.111

Table 1. Summary of research on using Industry 4.0 solutions in supply chain management (created by authors)

\begin{tabular}{|c|c|c|c|c|c|c|c|c|c|c|c|c|}
\hline \multirow[b]{2}{*}{ Author } & \multirow[b]{2}{*}{ Year } & \multirow{2}{*}{$\begin{array}{l}\text { Connec- } \\
\text { tion of In- } \\
\text { dustry } 4.0 \\
\text { to Digital } \\
\text { twin }\end{array}$} & \multicolumn{10}{|c|}{ Industry 4.0 methods in SCM } \\
\hline & & & $\begin{array}{l}\text { Simula- } \\
\text { tion }\end{array}$ & $\begin{array}{l}\text { Optimiza- } \\
\text { tion }\end{array}$ & $\begin{array}{l}\text { IoT \& } \\
\text { Block } \\
\text { chain }\end{array}$ & $\begin{array}{l}\text { Cyber } \\
\text { security }\end{array}$ & Big data & $\begin{array}{l}\text { Data Ana- } \\
\text { lytics \& } \\
\text { BI }\end{array}$ & $\begin{array}{l}\text { SC moni- } \\
\text { toring }\end{array}$ & $\begin{array}{l}\text { SC design } \\
\& \text { NOM }\end{array}$ & $\left|\begin{array}{lr}\mathrm{SC} & \text { risk } \\
\text { analytics }\end{array}\right|$ & Other \\
\hline $\begin{array}{l}\text { Borovkov et } \\
\text { al. }\end{array}$ & 2018 & + & + & + & + & & + & & & & & + \\
\hline Ivanov et al. & 2019 & & + & + & + & & & + & + & + & + & + \\
\hline Jeon and Suh & 2018 & + & + & + & + & & & & & & & + \\
\hline $\begin{array}{l}\text { Kunath and } \\
\text { Winkler }\end{array}$ & 2018 & + & + & & & & & + & & & & + \\
\hline Müller, et al. & 2018 & + & + & & & & & & & & & + \\
\hline Dittrich, et al. & 2019 & + & + & & & & & + & & + & & + \\
\hline Essakly et al. & 2019 & + & + & & + & + & + & & & & & + \\
\hline $\begin{array}{l}\text { Ivanov and } \\
\text { Dolgui }\end{array}$ & 2019a & & & & & & + & + & & + & + & + \\
\hline Ivanov et al. & 2019 & & + & + & & & + & + & + & + & + & + \\
\hline Jones et al. & 2020 & + & + & + & + & & + & & & & & + \\
\hline $\begin{array}{l}\text { Unity Tech- } \\
\text { nologies }\end{array}$ & 2019 & + & & & & & & + & & + & & + \\
\hline $\begin{array}{l}\text { Mantravadi, } \\
\text { and Møller }\end{array}$ & 2019 & & & & & & & + & & & & + \\
\hline Matsuda et al. & 2019 & & + & & & & & + & & + & & + \\
\hline Medini et al. & 2019 & + & + & + & + & + & + & + & & & & + \\
\hline Pan, S. & 2019 & + & & & + & & & & + & + & + & + \\
\hline Popkov, et al. & 2019 & & + & + & & & & + & & & & + \\
\hline Singh et al. & 2019 & & & & + & & + & + & & & & + \\
\hline
\end{tabular}

\section{Concept of a Supply Chain Digital Twin}

All these differences lead us to an obvious conclusion - traditional supply chains may no longer be sufficient in the digital transformation era. Modern markets demand not only efficiency from supply chains, but agility and flexibility as well. Today's supply chain is evolving from the traditional model of linear, individual, dis-synchronized relations into a more connected and harmonized network of trading partners. This renovated supply chain is expected to be digital and able to provide on-demand services. So, it has to be transformed through digital interconnected devices and complex networks. This digital supply chain would link different stakeholders (including customers) more efficiently, enabling them to react faster and to better adapt to a fast-changing market. Transition from Traditional Supply Chain to Digital Supply Chain was originally disclosed by De Souza (De Souza et al., 2017).

Capgemini Consulting (Raab and Griffin-Cryan, 2011) explains five transformation dimensions as follows: 
International Journal of Mathematical, Engineering and Management Sciences

Vol. 5, No. 6, 1498-1515, 2020

https://doi.org/10.33889/IJMEMS.2020.5.6.111

\subsection{Digital Supply Chain Strategy}

The aim is to integrate digital initiatives into the overall supply chain strategy.

\subsection{Supply Chain Operating and Governance Model.}

It is a special digital operating model, in which data is no longer depending on location. Large companies operating on a global scale will consider in more detail internal alignment committees.

\subsection{Integrated Execution}

It is of great importance to implement various supply chain functionality. The key goal is to develop an end-to-end processes providing employees with all the information they need.

\subsection{Integrated Supply Chain Performance Measurement}

This feature gives the opportunity to trace every order or transaction via Digital Operating Model. Tagging technologies, when one starts using barcodes or RFID marks, open a way to receive realtime data regarding physical relocation.

\subsection{Supply Chain Technology Architecture and Infrastructure Technology Architec- ture}

These types of architecture include the design logic for business processes and IT infrastructure t. As a result of McKinsey analysis of challenges that a new supply chain operating model offers, the scientist provided seven obligatory activities to help producers and retailers improve their supply chain operating model (Kuntze et al., 2019). A next-generation model offers the correct preliminary conditions to receive maximum benefit from supply chain digitalization. Companies can become even more competitive for a long period of time. These seven steps for operating model improvement should change the supply chain as follows:

\section{(i) Unconditional Challenge}

Modern and successful companies review all planning and logistics management processes of their company and are ready to seriously redesign the latter.

Digitization offers a better integration of planning and management steps. For example, optimization of the following areas like tactical production planning and operational scheduling. The company receives better planning results and can easier automate end-to-end processes. In the course of the said review, every process should be discussed and all the steps that don't add value should be removed.

\section{(ii) Cross-Functional Teams Deployment}

Recently, each supply chain process specialization. But when every unit starts optimizing itself, general efficiency goes down. Major companies decided to stop this overspecialization.

\section{(iii) Centralization}

Procter \& Gamble or Unilever and other large companies have been centralizing their planning and logistics management at a regional or even global level for a long time. It helps organizations to accumulate materials and construct centers of excellence and implement advanced analytics.

(iv) Assigning project Teams with Technology Development

Digital giants like Amazon and Zalando have already using a policy of stacking commercial process 
International Journal of Mathematical, Engineering and Management Sciences

Vol. 5, No. 6, 1498-1515, 2020

https://doi.org/10.33889/IJMEMS.2020.5.6.111

ownership and technology development. In this regard, companies should do the same and assign small, high-performance product teams to develop new technology solutions, instead of their large IT departments.

These groups include cross-functional staff and can take responsibility for fast and efficient development of innovative solutions. This approach, for example, helped a retailer to improve an order management module and address the issue of its constant delays within budget in a short period of time.

\section{(v) Decision-Making Process Acceleration}

Digital supply chain innovations in pilot projects require flexible tests. That is why agile principles implementation is connected with continuous progress monitoring as well as strict decisions on continuation or stopping the project.

\section{(vi) A Zero-Based Approach Adoption}

It is very difficult to change organizational structure or redistribute resources.

\section{(vii) Building Up Dynamic Capabilities}

Data scientists (analytical solutions and algorithms development experts) and digital translators (employees at the interface between business and analytics) are of particular importance. But sometimes it is difficult to train the right personnel within the company itself.

We could agree with the McKinsey's research (Alicke et al., 2017) proving that the potential benefits of Supply Chain 4.0 in consumer goods are multiple. The expectations are as follows: 75 percent fewer lost sales, up to 30 percent lower operational costs as well as up to 75 percent decrease in inventories. Additionally, the agility of the supply chains rises sharply. McKinsey's analysis shows a high correlation of three performance indicators.

- Supply-chain service/lost sales.

- Improved interaction with the customer via the supply chain significantly increases service level. - Supply chain costs. Changes in transportation, warehousing and overall network organization can reduce costs by up to 30 percent. Advanced methods of calculating the clean-sheet costs (bottom-up calculation of the "true" costs of services) of transportation and warehousing as well as network optimization can lead to about 50 percent of this improvement. The goal is to have minimum touch points and minimum distance driven at a high level of customer service.

For planning or forecasting only basic algorithms are used. Only a few data scientists are required to improve company's digital maturity.

McKinsey offered an important observation, which should also be noticed in view of digital transformation considering that IT sector is organized around a set of modular "platforms" (Bossert and Desmet, 2019). The question of how thorough or detailed a simulation should be for it to be called the digital twin of a supply chain and which questions are answered during the simulation process is also debatable. The minimum set of functions a supply chain digital twin should have are as follows:

_ planning the location of the facility; 
International Journal of Mathematical, Engineering and Management Sciences

Vol. 5, No. 6, 1498-1515, 2020

https://doi.org/10.33889/IJMEMS.2020.5.6.111

— center of gravity method or the Greenfield Analysis (GFA);

- Network Optimization method (NOM) using a mixed linear programming;

- planning the throughput of distribution centers;

— creating inventory management and order policies;

— creating a supply management policy (one or several suppliers);

— creating a transport policy (full truckload / FTL or less-than-truckload / LTL)

accounting for restrictions in transportation, production, and sales;

— risk analysis in the supply chain.

A view of the conceptual model of a supply chain digital twin is presented by the AnyLogic Company In our opinion, the conceptual model of a supply chain digital twin presented by the AnyLogic Company is sufficiently complete, including such methods as scenario planning, analytic optimization methods (GFA, NOM, Vehicle routing problem (VRP)), simulation, and support of management decision making.

Paper Ivanov (2018) notes that a combination of simulation modeling, optimization, and data analytics makes up the complete range of technologies needed to create a supply chain digital twin model. This model is integrated with online data flow and can be used in risk management. Ivanov D. considers the interaction of the supply chain digital twin with a Risk Data Monitoring Module, BI Systems, and ERP System.

Along with choosing the concept for a supply chain digital twin, it is necessary to select a covering or instrumental environment, in which simulation and optimization are carried out. Simulation modeling packages like ARENA, EXTEND, AnyLogic, Anylogistix, as well as instrumental environments designed for the quick development and deployment of solution optimization models using mathematical programming such as IBM ILOG CPLEX Optimization Studio, Analytic Solver Platform, and others, can be used as the instrumental environment for simulation and optimization.

Conceptual model of a supply chain digital twin was considered by D. Ivanov [(Ivanov, 2018), p. 11].

As a rule, creating a detailed supply chain model which can be called a digital twin requires the simultaneous use of simulation and optimization. For example, if Anylogistix acts as the instrumental environment then the architecture of the supply chain digital twin will look like what is presented in Figure 3. 


\section{AnyLogistix}

\section{Supply chain model}

Analytic optimization (IBM ILOG CPLEX Optimization Studio)

Linear programming.

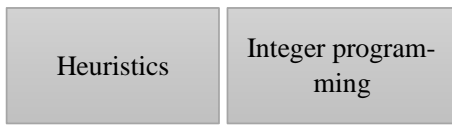

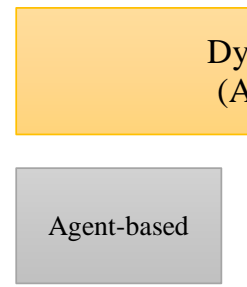

Dynamic simulation

(AnyLogic + Java)
Discrete-event simulation

System dynamics

Figure 3. Architecture of a supply chain digital twin in Anylogistix

If IBM ILOG CPLEX Optimization Studio is used as the instrumental environment, the architecture of the supply chain digital twin will look like one presented in Figure 4.

In the approaches examined above, the analytic optimization is used in order to determine the optimal coordinates for the location of new facilities (distribution centers, warehouses) using the Greenfield Analysis (GFA) or Network Optimization (NOM) methods, while the dynamic simulation allows a highly detailed modeling to be done of the processes taking place at production sites and logistics infrastructure facilities.

\section{IBM ILOG CPLEX Optimization Studio}

\section{Supply chain model}

Analytic optimization (CP Optimizer)

\section{Linear program-} ming
Heuristics
Integer programming
Dynamic simulation

(CPLEX C++, CPLEX for Python)

Agent-based
Discrete-event simulation
System dynamics

Figure 4. Architecture of a supply chain digital twin in IBM ILOG CPLEX optimization studio 
International Journal of Mathematical, Engineering and Management Sciences

Vol. 5, No. 6, 1498-1515, 2020

https://doi.org/10.33889/IJMEMS.2020.5.6.111

Interaction of a supply chain digital twin with risk management module and other external systems were developed by D. Ivanov [(Ivanov, 2018), p. 10]

The differences in the approaches can be seen in that, in the first case, the environment for developing the supply chain digital twin is the system Anylogistix, which is integrated with CPLEX in order to find the optimal number and location of supply chain nodes using GFA and NOM. It also uses the plug-ins AnyLogic and Java, which help create algorithms which model facilities and processes with complex logic. In the second case, the development environment is IBM ILOG CPLEX Optimization Studio, which allows a supply chain to be simulated at both the macro and micro level. This development environment has built-in modules and programming languages which help to create detailed supply chain models to the necessary level of intricacy. Thus, in the approach used in the first case, the analytical optimization is a complement to the dynamic simulation, while in the second case, the dynamic simulation is a complement to the analytical optimization.

There is a question on which of the approaches examined above should be granted preference. In our opinion, the advantage of the first approach is the "friendliness" of the Anylogistix environment for novices. Beginners can create a chain supply model with a simple logic in Anylogistix. Experienced users can create a supply chain model of medium complexity via basic functionality of AnyLogic but without programming. Creating a supply chain digital twin requires a detailed description of the facilities and processes, complex logic tasks, creating experiments, collecting statistics, and integration of the model with an ERP system and BI systems. Of course, creating a supply chain model in CPLEX requires the developer to have a deep understanding of the system itself, particularly the CP Optimizer module, as well as the use of a programming language (C++, Python).

The connection between the level of proficiency in Anylogistix/CPLEX and the complexity of the model created is presented in Table 2.

Table 2. Connection between the level of proficiency in anyLogistix/CPLEX and the complexity of the supply chain model created (developed by the authors)

\begin{tabular}{|l|l|l|l|l|l|}
\hline \multirow{2}{*}{$\begin{array}{l}\text { Complexity of } \\
\text { the SC model }\end{array}$} & \multicolumn{4}{|c|}{ Level of proficiency in Anylogistix } & \multicolumn{2}{c|}{$\begin{array}{c}\text { Level of proficiency in } \\
\text { CPLEX }\end{array}$} \\
\cline { 2 - 6 } & Novice user & $\begin{array}{c}\text { Experienced user } \\
\text { (AnyLogic) }\end{array}$ & $\begin{array}{c}\text { Advanced user } \\
\text { (AnyLogic + basic } \\
\text { Java) }\end{array}$ & $\begin{array}{c}\text { Expert } \\
\text { (AnyLogic + Java) }\end{array}$ & $\begin{array}{c}\text { Expert } \\
\text { (CP Optimizer, C++, Py- } \\
\text { thon) }\end{array}$ \\
\hline Low & $\begin{array}{l}\text { Network facil- } \\
\text { ities, simple } \\
\text { logic }\end{array}$ & $\begin{array}{l}\text { Network facili- } \\
\text { ties, complex } \\
\text { logic, processes }\end{array}$ & $\begin{array}{l}\text { Network facilities, } \\
\text { complex logic, pro- } \\
\text { cesses, replacement } \\
\text { and supply policies, } \\
\text { statistics }\end{array}$ & $\begin{array}{l}\text { Network facilities, } \\
\text { complex logic, pro- } \\
\text { cesses, replacement } \\
\text { and supply policies, } \\
\text { statistics, algorithms, } \\
\text { experiments, integra- } \\
\text { tion with ERP }\end{array}$ & $\begin{array}{l}\text { Network facilities, com- } \\
\text { plex logic, processes, re- } \\
\text { placement and supply poli- } \\
\text { cies, statistics, algorithms, } \\
\text { experiments, integration } \\
\text { with ERP }\end{array}$ \\
\hline Medium & & & & \\
\hline Increased & & & &
\end{tabular}


International Journal of Mathematical, Engineering and Management Sciences

Vol. 5, No. 6, 1498-1515, 2020

https://doi.org/10.33889/IJMEMS.2020.5.6.111

Thus, Anylogistix does not present the developer of a supply chain model with as high of demands in comparison to the development environment IBM ILOG CPLEX Optimization Studio. Even novice users can create a simple supply chain model in Anylogistix. However, the functionality of this model is limited to determining the optimal coordinates for the location of new facilities (distribution centers, warehouses) using the GFA or NOM methods. Creating supply chain models with complex logic, a detailed simulation of processes, replacement and supply policies, collection of statistics, as well as conducting experiments with these models and integrating them with ERP requires bringing in experts and professionals in the field of simulation modeling. Consequently, highly qualified professional programmers are needed to create a supply chain digital twin both in Anylogistix and in IBM ILOG CPLEX Optimization Studio.

However, analyzed literature shows a consolidated and consistent view on what the Digital Twin is as well as on the way of the concept's evolvement in order to meet the needs of many use-cases. The lack of consistency has led to multiple definitions of digital twinning processes. It can negatively affect the original cause of Digital Twin as well as lead to missed benefits. The virtual spaces themselves can consist of any number of sub-spaces with specific virtual features like modelling, testing, optimization, etc.

Mirroring or Twinning between the physical and virtual spaces was considered [(Jeon and Suh, 2018), p. 2].

An analytical description of the generalized concept of digital twins is presented in the paper of (Jones et al., 2020). The paper examines the two processes of creating twins - physical-virtual and virtual-physical. These processes are called twinning. The connection between the physical and virtual process when creating a digital twin was studied [(Jeon and Suh, 2018), p. 9].

The combination of both connections makes it possible to optimize a continuous cycle since the possible physical states are predicted in the virtual environment and are optimized for a specific purpose. In other words, the process of virtual optimization is carried out using the current state of the physical/virtual facility. After this is determined, this optimal set of virtual parameters is transferred to the physical twin. The physical twin then reacts to the change, and the process is cyclically repeated in order to update the virtual twin with the physical state measured. After this, it is possible to compare the delta between the actual and predictable states and restart optimization with updated information.

It is clear that both of the twinning processes are of important value when creating a supply chain digital twin. Figure 5 presents a generalized view of the technology for a supply chain digital twin.

In our opinion, the main technologies which turn a physical supply chain into its digital twin (Physical-Virtual Twinning) are simulation, analytical optimization, and data analytics. These technologies are placed in the center of the twinning cycle above the line dividing the virtual and physical environments. The main technologies converting a digital twin into a physical supply chain (VirtualPhysical Twinning) are supply chain reconfiguration and re-engineering. These technologies are also placed in the center of the twinning cycle below the line dividing the virtual and physical environments. Above the twinning cycle other technologies of a supply chain digital twin can be found, while under the twinning cycle there are technologies which are associated with the physical processes in supply chains (Open and Flexible Operations Footprint, No Warehouse in Supply Chain, and Autonomous Transportation Vehicle / Equipment). 
International Journal of Mathematical, Engineering and Management Sciences

Vol. 5, No. 6, 1498-1515, 2020

https://doi.org/10.33889/IJMEMS.2020.5.6.111

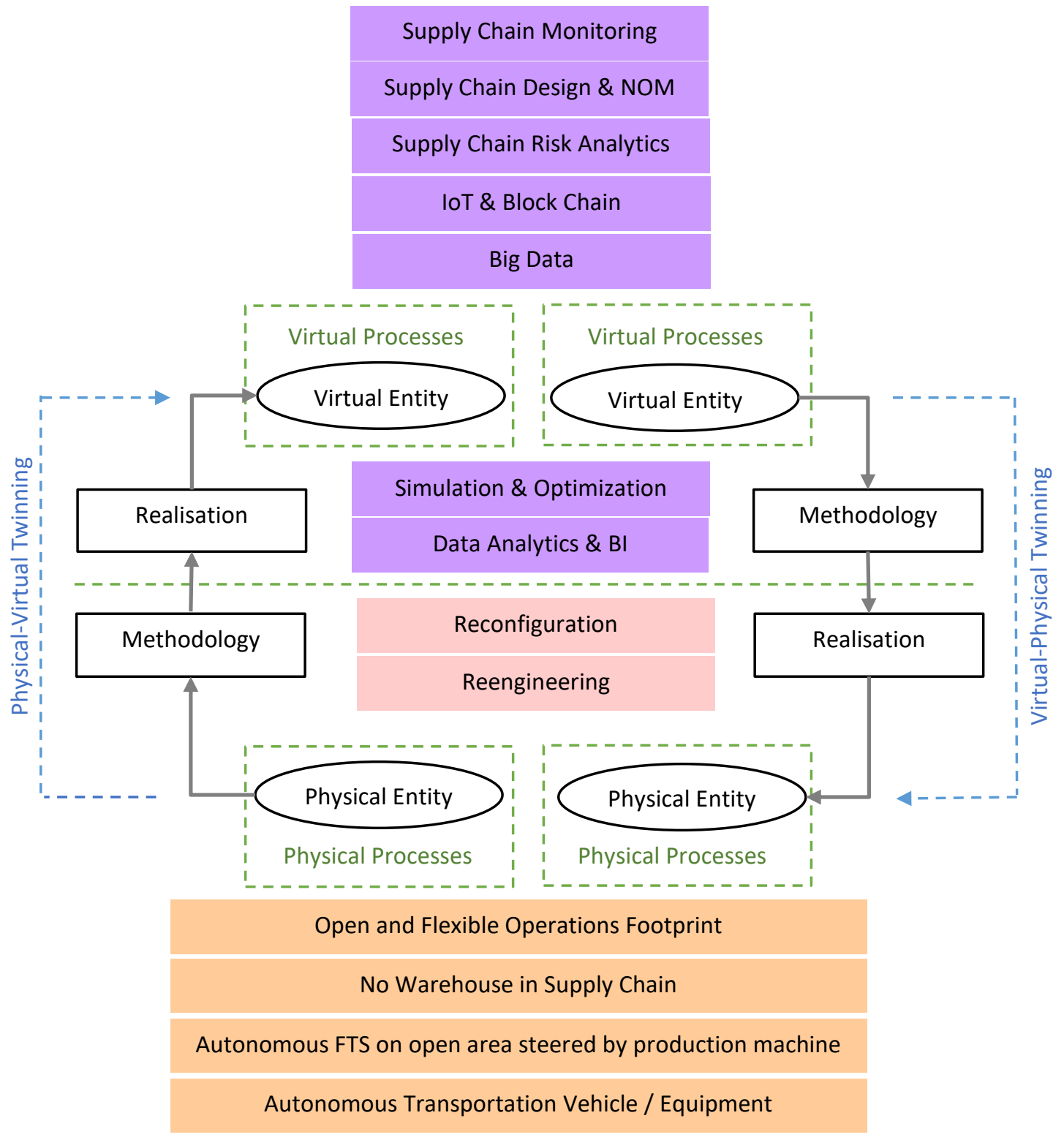

Figure 5. Generalized technology of a supply chain digital twin (created by authors)

\section{Conclusion}

The conducted research shows that according to most experts, a combination of simulation modeling, optimization, and data analytics makes up the full range of technologies which are needed to create a supply chain digital twin model. This model is integrated with an online data flow and can be used in risk management. By simulating and planning scenarios, it is possible to observe the impact various failures in the supply chain and recovery policy have on its productivity. By inputting changes into the supply chain digital twin model, it becomes possible to understand the dynamics of a physical supply chain. 
International Journal of Mathematical, Engineering and Management Sciences

Vol. 5, No. 6, 1498-1515, 2020

https://doi.org/10.33889/IJMEMS.2020.5.6.111

The conceptual model for a supply chain digital twin which was examined includes methods such as scenario planning, analytic optimization (GFA, NOM, VRP), simulation modeling, and support for management decision making. Also the advantages and drawbacks of such tools as anyLogistix and IBM ILOG CPLEX Optimization Studio used for creating a supply chain digital twin were examinated. The level of proficiency in Anylogistix, CPLEX, and other similar tools is a key factor when creating supply chain models with complex logic. Creating a supply chain digital twin requires the expertise of specialists in the field of simulation modeling as well as professional programmers.

A summary of the technology of a supply chain digital twin was presented (see Figure 5). This technology helps to: 1) clarify the concept of twinning; 2) clarify the connection between physical supply chains and their digital twins; 4) specify the area of application for the different digital twin technologies. In this way, the generalized digital twin technology can serve as a conceptual foundation for creating a supply chain digital twin.

\section{Points for Scientific Discussion}

Supply chain digital twins are a special object of study by their nature, differing from digital twins of other physical facilities and processes. This is dictated by the very nature of the logistics configuration of supply chains as well as the specific nature of the relation of the virtual model and the supply chain in the real world. The technologies for reconfiguring and re-engineering supply chains can be placed at the center of the twinning cycle under the line dividing the virtual and physical environments.

The research we have conducted is of a rather pilot nature and leaves a number of questions without a definitive answer. Two questions which can be presented for discussion among the scientific community are, first of all, the question of which combination of simulation modeling, optimization, and data analytics makes up the full range of technologies needed to create a supply chain digital twin and, secondly, the question about which technologies other than reconfiguration and re-engineering should be used for transforming a digital twin into a physical supply chain. The sources examined in this work point out recovery or reconditioning as well as utilization or recycling as such technologies. In our opinion, these technologies are about smart factories but not to the supply chain digital twins.

\section{Conflict of Interest}

The authors confirm that there is no conflict of interest to declare for this publication

\section{Acknowledgements}

This research work was supported by the Academic Excellence Project 5-100 proposed by Peter the Great St. Petersburg Polytechnic University.

\section{References}

Borovkov, A., \& Ryabov, Y. (2019). Digital twins: definition, approaches and methods of development. In Babkin A.V. (ed.), Digital Transformation of Economy and Industry. Works of the X Research-toPractice Conference with Foreign Participation 20-22 June 2019 (pp. 234-245). Peter the Great St. Petersburg Polytechnic University, St Petersburg, Russia https://doi.org/10.18720/IEP/2019.3/25. 
International Journal of Mathematical, Engineering and Management Sciences

Vol. 5, No. 6, 1498-1515, 2020

https://doi.org/10.33889/IJMEMS.2020.5.6.111

A new paradigm of digital design and modeling of globally competitive products of the new generation. Working report of the Department of Corporate Education of the Moscow School of Management Skolkovo «Digital Production: Methods, Ecosystems, Technologies». 2018. Pp. 24-43. (In Russ.). Available at: http://assets.fea.ru/uploads/fea/news/2018/04_april/12/cifrovoeproizvodstvo-032018.pdf.

De Souza, R., William, L., \& Timperio, G. (2017). Supply chain digital transformation: insights and tools anylogistix supply chain optimization software. https://www.anylogistix.com/resources/whitepapers/supply-chain-digital-transformation-insights-and-tools/.

Dittrich, M.A., Schleich, B., Clausmeyer, T., Damgrave, R., Erkoyuncu, J.A., Haefner, B., de Lange, J., Plakhotnik, D., Scheidel, W., Wuest, T. (2019) Shifting value stream patterns along the product lifecycle with digital twins. In Procedia CIRP, 86. 3-11.

Essakly, A., Wichmann, M., \& Spengler, T.S. (2019). A reference framework for the holistic evaluation of Industry 4.0 solutions for small- and medium-sized enterprises. IFAC-PapersOnLine, 52(13), 427-432.

Ivanov. (2018). Supply chain simulation and optimization with anyLogistix: teaching notes. Berlin School of Economics and Law, Germany. https://www.anylogistix.ru/resources/books/alx-textbook/.

Ivanov, D., \& Dolgui A. (2019a). New disruption risk management perspectives in supply chains: digital twins, the ripple effect, and resileanness. 9th IFAC Conference on Manufacturing Modelling, Management and Control (MIM 2019), edited by Dmitry Ivanov, Alexandre Dolgui, Farouk Yalaoui, IFAC-PapersOnLine 52(13), 337-342.

Ivanov, D., \& Dolgui, A. (2019b) New disruption risk management chains: digital twins, the ripple effect, and resileanness. IFAC Papers On Line. 52(13). 337-342.

Ivanov, D., Dolgui A., Ivanova, M., \& Sokolov, B. (2019) Intellectualization of control: cyber-physical supply chain risk analytics. 9th IFAC Conference on Manufacturing Modelling, Management and Control (MIM 2019), edited by Dmitry Ivanov, Alexandre Dolgui, Farouk Yalaoui. IFAC-PapersOnLine 52(13), 355-360.

Jeon, B., \& Suh, S.H. (2018). Design considerations and architecture for cooperative smart factory: MAPE/BD approach. Procedia Manufacturing, 26, 1094-1106.

Jones, D., Snider, C., Nassehi, A., Yon, J., \& Hicks, B. (2020). Characterising the digital twin: a systematic literature review. CIRP Journal of Manufacturing Science and Technology, 29, 36-52.

Kauf, S. (2019). Smart logistics as a basis for the development of the smart city. Transportation Research Procedia, 39(2018), 143-149. https://doi.org/10.1016/j.trpro.2019.06.016.

Alicke, K., Rexhausen, D., \& Seyfert, A. (2017). Supply chain 4.0 in consumer goods. Mckinsey \& Company, 1-11. https://www.mckinsey.com/industries/consumer-packaged-goods/our-insights/supply-chain-4-0in-consumer-goods.

Kunath, M., \& Winkler, H. (2018). Integrating the digital twin of the manufacturing system into a decision support system for improving the order management process. Procedia CIRP, 72, 225-231. https://doi.org/10.1016/j.procir.2018.03.192.

Kuntze, C., Lange, T., \& Seyfert, A. (2019). Next-generation supply chain — transforming your supply chain operating model for a digital world. McKinsey \& Company, June, 5.

Le, D.N., Nguyen, H.T., \& Truong, P.H. (2020). Port logistics service quality and customer satisfaction: Empirical evidence from Vietnam. The Asian Journal of Shipping and Logistics, 36(2), 89-103.

Ljovkina, A.O., Dusseault, D.L., Zaharova, O.V., \& Klochkov, Y. (2019). Managing innovation resources in accordance with sustainable development ethics: Typological analysis. Resources, 8(2), 1-17.

Logistics 4.0 and smart supply chain management in Industry 4.0. https:/www.i-scoop.eu/industry-40/supply-chain-management-scm-logistics/. 
International Journal of Mathematical, Engineering and Management Sciences

Vol. 5, No. 6, 1498-1515, 2020

https://doi.org/10.33889/IJMEMS.2020.5.6.111

Mantravadi, S., \& Møller, C. (2019). An overview of next-generation manufacturing execution systems: how important is MES for industry 4.0? Procedia Manufacturing, 30, 588-595.

Matsuda, M., Nishi, T., Hasegawa, M., \& Matsumoto, S. (2019) Virtualization of a supply chain from the manufacturing enterprise view using e-catalogues. Procedia CIRP, 81, 932-937.

Bossert, O., \& Desmet, D. (2019) McKinsey Digital. The platform play: How to operate like a tech company. In McKinsey Digital (Issue February). https://www.mckinsey.com/business-functions/digitalmckinsey/our-insights/the-platform-play-how-to-operate-like-a-tech-company?cid=other-eml-alt-mipmck\&hlkid=ccf80d89e6764dd0887de7146b84e435\&hctky=2233918\&hdpid=2854d7d9-a2e5-4926afe4-eef4223ca8f5.

Medini, K., Andersen, A.L., Wuest, T., Christensen, B., Wiesner, S., Romero, D., Liu, A., \& Tao, F. (2020). Highlights in customer-driven operations management research. Procedia CIRP, 86, 12-19. https://doi.org/10.1016/j.procir.2020.01.026.

Müller, R., Vette-Steinkamp, M., Hörauf, L., Speicher, C., \& Burkhard, D. (2018). Development of an intelligent material shuttle to digitize and connect production areas with the production process planning department. Procedia CIRP, 72, 967-972. https://doi.org/10.1016/j.procir.2018.03.216.

Pan, S. (2019). Opportunities of product-service system in physical internet. Procedia CIRP, 83, 473-478.

Petrović, I., Muhammad, A., \& Muhammad, A. (2020). Open platform based mobile robot control for automation in manufacturing logistics. IFAC-PapersOnLine, 52(22), 95-100. https://doi.org/10.1016/j.ifacol.2019.11.055.

Popkov, T., \& Zherebtscov, A. (2019) Design your supply chain run with digital twin. https://www.anylogic.ru/upload/conference/2019/presentations/anylogistix-create-your-supply-chaindigital-twin.pdf.

Raab, M., \& Griffin-Cryan, B. (2011). Digital transformation of supply chains. Creating Value-When Digital Meets Physical, Capgemini Consulting. https://www.capgemini.com/resources/digital-transformationof-supply-chains/.

Singh, S., Barde, A., Mahanty, B., \& Tiwari, M.K. (2019). Digital twin driven inclusive manufacturing using emerging technologies. IFAC-PapersOnLine, 52(13), 2225-2230.

Supply chain digital twins. https://www.anylogistix.ru/supply-chain-digital-twins/.

Tarasov, I.V. (2018) Industry 4.0: concept, ideas, and tendencies of development. Business Strategies, 6(50), 57-63.

Ferreira, W.D.P. (2019). IDE OPL (Optimization Programming Language) Apresentado por: William de Paula Ferreira. April

Vorobyov, S., Perlovsky, L., \& Yadykin, V. (2019). Reasoning and learning in a digital economy. technological challenges of the modern age. IOP Conference Series: Materials Science and Engineering, 497(1), 012038. https://doi.org/10.1088/1757-899X/497/1/012038. 